\title{
The Mental Health Advice Centre in Lewisham
}

\section{I. Brough, N. Bouras and J. P. Watson, Multiprofessional Mental Health Advice Centre, London.}

Psychiatric disorders in the community are very common and most are dealt with by GPs, only a small proportion reaching psychiatrists (Goldberg and Huxley, 1980; Shepherd et al, 1981). It has been suggested that a large proportion of the psychiatric problems seen by GPs are intimately related to adverse life events and difficulties (Ingham, 1981; Tennant et al, 1981).

Psychiatry's traditional concern with the treatment of psychosis has been accompanied by planned devolution of facilities from large institutions into District General Hospitals where psychiatry may be more closely associated with other acute specialties. This process has been slow even in regions and districts regarded as 'over-resourced' in 'RAWP' terms (Brough and Watson, 1977), and increasing demand for community psychiatric facilities in recent years has suggested that radical changes in the organization and delivery of mental health services may be necessary if these demands are to be met, even partially.

The effectiveness of the psychiatric help provided by primary care agents has started to be questioned (Brook and Cooper, 1975) and it has been suggested that the psychiatrist should collaborate more closely with primary care services (World Health Organization, 1973). Ways of doing this include the psychiatrist doing regular sessions in health centres (Corser and Ryce, 1977; Brook, 1978) and attaching psychologists (Johnstone, 1978) or social workers (Cooper et al, 1975; Corney and Briscoe, 1977; Shepherd et $a l, 1979)$ to GPs to form enlarged primary care teams.

A major problem associated with these approaches is how to staff facilities if service is to be widely available. We describe here the development of a different type of community psychiatric service. It is based in Lewisham, SE London, where several different professionals work together in a Centre with the objectives of providing easy access for patients and close collaboration with GPs.

\section{The service}

The former Lewisham Health District before reorganization comprised a sociologically-mixed population of 200,000 in SE London and although situated in an over-resourced region the psychiatric services were, and are, seriously inadequate. There are in-patient beds at Bexley Hospital, 12 miles away, but no psychiatric beds in the district hospital, no day hospital and only limited access to hospital outpatient facilities.

In 1976 a small group developed a domiciliary-based project for assessment and treatment, without additional cost. This project created interest and was eventually supported by the statutory authorities, both health service and local authority, and by the Community Health Council and the Association of Mental Health.
Within two years a team moved into a vacant suburban house (leased to the Lewisham District Management Team) which became known as the Mental Health Advice Centre (MHAC).

This Centre serves a catchment area of 82,000 people within the age range 18-64 years, which is the area of medical responsibility of one of us (DIB). It is in a pleasant residential area, easy to reach by public transport, and it looks like an ordinary house with none of the associations of a hospital clinic. There is office space, room for group conferences, interview rooms, a rehabilitation office and a research department.

The Centre, opened in November 1978, was from the outset staffed by a multi-professional team (MPT) which has steadily grown and today comprises 17 members including psychiatrists, clinical psychologists, community psychiatric nurses, psychotherapists, occupational therapists, community social workers, research workers, volunteers and the team manager. This MPT thus evolved over a period of some years. From the outset, time each week has been set aside for policy discussions, and the team's activities have been monitored. The importance of a clearly identified leader and director for the Centre became evident at an early stage, and one of us (DIB) has occupied both these positions; together with the other authors (NB and JPW) he shares responsibility for the research aspects of the enterprise, as the latter are not directly involved with the Centre's clinical work. The nature of the leadership and the MPT is one of our continuing research interests.

A number of volunteers work at the Centre. They were recruited by the voluntary services organizer of Bexley Hospital. There was no selection procedure, but each volunteer was expected to take part in a training group with two of the team's professionals acting as co-leaders, for six months. By the end of the training period the volunteers decided whether to make a commitment in return for ongoing supervision and attendance at a monthly group.

Twelve unpaid volunteers now help vitally in the running of the Centre. They assist in the reception of the clients and may carry a small case load under direct professional supervision. There is also volunteer involvement in group work. Most volunteers are interested 'lay' persons, but some have relevant professional expertise, and have included a doctor, a social worker, a clinical psychologist and a nurse; they have proved a most valuable resource.

It has been necessary to create a policy and a records system, and to establish communication with 72 GPs, two social services divisions, local district nurses and health visitors, as well as many other community organizations.

One professional team member is at the Centre every weekday from $9.00 \mathrm{am}$ until $1.00 \mathrm{pm}$ to see new referrals. 
Patients (usually called clients) may be referred by their GP or their community agents, or may simply 'walk-in'. They do not need an appointment. Intake is, however, restricted strictly to people who live in the catchment area. In addition, the Centre does not serve children and elderly people for whom separate psychiatric services are available. Also, alcoholics and drug addicts are referred to more specialist clinics.

New clients are met by a volunteer and introduced to the on-duty professional, who then carries out an interview, makes an assessment and contacts the client's GP to seek information and to report on the visit. The MPT then discusses the client at one of the weekly conferences. If the person needs more help and treatment, one member is selected to be the 'key worker'. He maintains contact with the client, his GP and any other agencies involved, and coordinates any treatment programme. Any volunteers involved in this programme work under the supervision of the key worker. Currently, a major emphasis is on family therapy methods.

\section{An extended service}

Experience indicated that a number of emergency cases were unable to reach the Centre. A second team was therefore formed, supported by health service and joint financing funds-the Crisis Intervention Team (CIT). The CIT consists of a psychiatrist, a senior social worker and a community nurse, supervised by the consultant psychiatrist (DIB); the work is co-ordinated by the team's administrative secretary. The CIT responds to calls by GPs, social workers, nurses, health visitors and goes out to people's homes and other places, e.g. police stations. The CIT may operate with additional assistance from professional students, other professionals and volunteers where appropriate.

The social worker, psychiatrist and nurse work closely with considerable blurring of roles. They share a single office which facilitates informal discussion and exchange of ideas. The CIT works, Monday to Friday, between 9.00am and $5.00 \mathrm{pm}$, but is often active late into the evenings. It cooperates closely with GPs, and with an emergency social work team on duty in the Borough each weekend. Out-ofhours emergencies are dealt with in the traditional way by social services and GPs who liaise with the duty psychiatrist at Bexley Hospital.

Referrals to the CIT often include a request for admission and the task of the team is then to assess the need for this. Chief aims are to provide quick, effective intervention, to facilitate the resolution of the crisis, and to avoid hospitalization if a client can be helped in his home.

\section{Research}

A research department has been established to study the work and effects of the service. Social, demographic and clinical characteristics of the clients have been recorded systematically over the past three years, partly in order to correct misapprehensions which so readily can arise in a new, enthusiastic enterprise. It is also becoming possible to design studies to investigate questions derived from the clinical work. The research department has so far produced two reports, one referring to the work of the MPT and the other to the CIT.

A total of 1,112 clients were seen between 1979 and 1981 . Of these, 786 were seen by the MPT at the Centre and 326 by the CIT. The mean age was 36.5 years $(S D \pm 13.5)$. During the three years the socio-demographic profile of clients seen in each year was similar and there was no indication of a particular trend from one year to another. A considerable proportion of the clients were young married women. Many clients had a previous psychiatric history, for both teams, and particularly of hospital treatment among CIT clients.

Diagnoses were made using the eighth, and more recently ninth, editions of the ICD. The two main diagnoses in clients seen by the MPT were 'transient situational disturbance' (28.5 per cent) and 'personality disorder' (19.9 per cent). Functional psychoses accounted for $\mathbf{3 6 . 2}$ per cent of those seen by the CIT, but for only 10 per cent of those seen by the MPT. We have found that the ICD classification is unsatisfactory for the kind of problems seen at the MHAC and we are considering the use of a multi-axial classification.

Most clients seen by the two services received counselling and domiciliary support ( 50 per cent) for MPT and (44 per cent) for CIT. Prescription of drugs was provided, when necessary, by the GP. Specific treatments of other kinds were carried out at the Centre or at home with or without additional help from local social, community or out-patient psychiatric services or volunteers.

The large number of non-emergency referrals and the Centre's mode of working may be affecting changes in the referral behaviour suggested by Goldberg and Huxley (1980). In fact, their second and third filters (i.e. GPs' ability to detect psychiatric disorders among patients and refer them to psychiatric services) may simply be consequences of traditional organization of services.

Evidently, the MHAC has boen dealing with highly distressed people. The improved availability of psychiatric care through the Centre has been seen in a small consumer study; this showed almost unanimous satisfaction with the service received. The clients' preference to be seen in the informal setting of a house rather than a clinical hospital setting was especially stressed.

The MHAC has contributed to a more comprehensive service by making the expertise of a multi-professional team more readily available to both GPs and their patients. Treatment is encouraged in clients' homes and is more psychological than physical, ranging from highly individualized programmes to relatively non-specific therapies. Groups are supervised by professionals in the Centre and there is liaison with other community groups, who 
are also able to provide treatment. Thus, the MHAC has the effect of increasing the number of people who can receive that kind of 'talking' treatment which many clients find appealing.

Local enthusiasm for the Centre's work is considerable, but carefully designed follow-up studies are required before substantive claims can be made. Further research is also required before statements can be made about the costeffectiveness of the service. This is a complicated issue; it is not necessarily the case that our service is cheaper because it does not use the facilities of an expensive DGH.

There is already evidence that the MHAC is an innovation which has served some individuals not previously dealt with by a specialist service, and who may be presumed to have needs which previously went unmet. The Centre has also allowed patients previously dealt with by a specialist service to be approached differently. As the MHAC becomes established it is being regarded as a significant mental health resource for the community in which it is located.

\section{ACKNOWLEDGEMENTS}

We are grateful for the generous support of the Sainsbury Family Charitable Trust, the SE Thames RHA, the (former) Lewisham DMT and the MHAC League of Friends.

\section{REFERENCES}

Brook, A. (1978) An aspect of community mental health: Consultative work with general practice teams. Health Trends, 2, 37-9.

Brook, P. \& CoOper, B. (1975) Community mental health care: primary team specialist services. Journal of the Royal College of General Practitioners. 25, 93-110.
Brough, D. I. \& Watson, J. P. (1977) Psychiatric facilities in an over-resourced NHS region. British Medical Journal, in 905-6.

Cooper, B., Harwin, B. G., Depla, C. \& Shepherd. M. (1975) Mental health care in the community: an evaluative study. Psychological Medicine, 5, 372-80.

Corney, R. H. \& BRISCOE, M. E. (1977) Social workers and their clients: a comparison between primary health care and local authority settings. Journal of the Royal College of General Practitioners, 27, 295-307.

CoRser, C. M. \& RYCE, S. W. (1977) Community mental health care: a model based on the primary care team. British Medical Journal, it, 936-8.

Goldgerg, D. \& Huxley, P. (1980) Mental lliness in the Community: The Pathway to Psychiatric Care. London: Tavistock Publications.

INGHAM, J. (1981) Neurosis: Disease or distress? In What is a Case? (eds. J. K. Wing et al.). London: Grant McIntyre.

JoHNSTONE, M. (1978) The work of a clinical psychologist in primary care. Journal of the Royal College of General Practitioners, 28, 661-7.

Shepherd, M., Harwin, B. G., Depla, C. \& Calrns, V. (1979) Social work and the primary care of mental disorder. Psychological Medicine, 9, 661-9.

COOPER, B., Brown, A. C. \& KAlton, G. (1981) Psychiafric Illness in General Practice. Second Edition. London: Oxford University Press.

Tennant, C., Bebington, P. \& Hurry, J. (1981) The short-term outcome of neurotic disorders in the community: The relation of remission to clinical factors and to 'neutralising' life-events. British Journal of Psychiatry, 139, 213-20.

World Health Organization (1973) Psychiatry and Primary Medical Care. Copenhagen: WHO Regional Office for Europe.

\section{News Items}

\section{Prescribing Amphetamines}

The following extract, which is taken from Dr Ferris $\mathrm{N}$. Pitts' Editorial (Journal of Clinical Psychiatry, November $1982,43,438)$, may be of interest to readers:

The Editors know of one board-certified psychiatrist with postresidency training in psychopharmacology whose hospita privileges were suspended principally because he prescribed methylphenidate in one case of chronic depression and $d$ amphetamine in another. It is bizarre that the accusers of this psychiatrist were able to achieve their ends despite the systematic in-hospital demonstration that no other conceivable therapeutic regimen had any appreciable effect on these severe depressive illnesses, and despite the subsequent demonstration of the effectiveness of amphetamines in their treatment.

The Editors also know of at least one conscientious board certified psychiatrist whose medical licence has been suspended because he prescribed $10-30 \mathrm{mg} / \mathrm{day}$ (or the equivalent) of d- amphetamine to 8 of 58 chronic depressives followed carefully as outpatients. These 8 patients had failed to respond to weekly (or daily) psychotherapy plus adequate dosages of various tricyclics, neuroleptics, and monoamine oxidase inhibitors. With the introduction of reasonable dosages of amphetamines, 8 extremely il] and disabled persons became less ill and more functional; none showed evidence of increasing amphetamine dosage (tolerance and abuse).

Things have come to a pretty pass, to borrow a phrase from an earlier era, when conscientious physicians cannot practise their profession informedly without such ignorant and callous harassment. It is one thing to locate and discipline a few malicious physicians distributing controlled substances for money, but quite another to track down and harass conscientious physicians prescribing controlled substances rationally after good-faith examinations, unsuccessful attempts at therapy with other medications, and careful trials with the controlled substances in particular patients. 